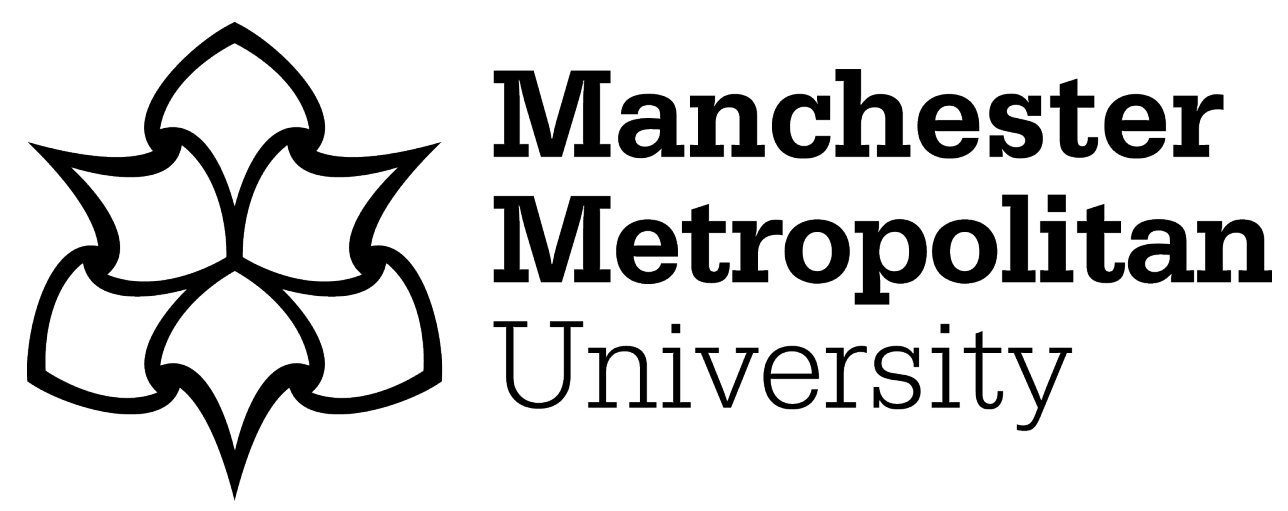

Noggerini, LN, Martins, VWB, Rampasso, IS, Quelhas, OLG, Leal Filho, W and Anholon, R (2022) Difficulties observed in hydroelectric turbine projects management: evidence from case studies. Kybernetes, 51 (12). pp. 34703486. ISSN 0368-492X

Downloaded from: https://e-space.mmu.ac.uk/628490/

Version: Accepted Version

Publisher: Emerald

DOI: https://doi.org/10.1108/K-03-2021-0179

Please cite the published version 


\title{
Difficulties observed in hydroelectric turbine projects management: evidence from case studies
}

\author{
Noggerini, L.N ${ }^{\mathrm{a}}$; Martins, V.W.B ${ }^{\mathrm{a}, \mathrm{b}}$; Rampasso, I.S ${ }^{\mathrm{a}, \mathrm{c}}$; Quelhas, O.L.G ${ }^{\mathrm{c}}$; Leal Filho, W ${ }^{\mathrm{e}}$; \\ Anholon, $\mathrm{R}^{\mathrm{a}}$
}

\section{Kybernetes 01 Jan 2021 doi.org/10.1108/K-03-2021-0179}

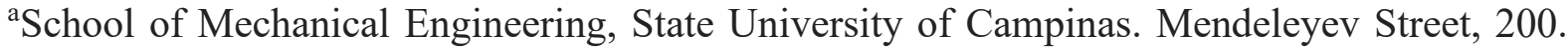 \\ Campinas, São Paulo, Brazil. \\ b Department of Production Engineering, State University of Pará, Travessa Dr. Enéas \\ Pinheriro, \\ 2626. Belém, PA, Brazil.
}

'Laboratory of Technology, Business and Environment Management. Federal Fluminense University. Passo da Pátria Street, 156. Niterói, Rio de Janeiro, Brazil. Phone: +55 19 32513312. e-mail: izarampasso@gmail.com

${ }^{\mathrm{d}}$ School of Mechanical Engineering, State University of Campinas. Mendeleyev Street, 200. Campinas, São Paulo, Brazil. Phone: +55 19 3251-3312. e-mail: rosley@fem.unicamp.br eEuropean School of Sustainability Science and Research, Faculty of Life Sciences, Hamburg University of Applied Sciences, Ulmenliet 20, D-21033 Hamburg Germany. e-mail: walter.leal2@haw-hamburg.de

Correspondent author: izarampasso@gmail.com

\begin{abstract}
Purpose: This study aims to analyze the difficulties observed in the management of three hydroelectric turbine projects developed by a large multinational company in the metalmechanic segment, identifying those most critical.

Design/methodology/approach: Through a bibliographic search, difficulties throughout project management were identified. These difficulties were used as a research protocol to carry out three case studies in a hydroelectric turbine manufacturer. The projects selection aimed to
\end{abstract}


contemplate different characteristics to encompass the diversity of their typologies. Data were analyzed through content analysis technique and the difficulties were ordered via Grey Relational Analysis (GRA).

Findings: Qualitative data analysis provided specific insights regarding the characteristics of each project. When analyzing the difficulties of hydroelectric turbine projects management via Grey Relational Analysis (GRA), it is observed that those difficulties most evidenced were related to integration and communication, suppliers management, and objectives definition.

Originality/value: The main contribution of this research lies in the sector under analysis. The literature about hydroelectric turbine projects is scarce. In addition, no similar studies were found in the literature.

Keywords: Project management; Difficulties; Hydroelectric Turbines; Case study; GRA.

\section{Introduction}

The search for better results requires companies to constantly improve management models used and techniques adopted (Carvalho et al., 2015; Saeed et al., 2020). To ensure good organizational performance, it is necessary to invest in new approaches, manage the costs, improve existing management tools, understand customers' requirements and constantly innovate responsibly and sustainably (Sanchez et al., 2017).

There are many management concepts and tools that can positively contribute to achieving better results in companies. Among them, project management is highlighted (Aleksic et al., 2017; Anholon and Sano, 2016). Projects involve the development of something that has never been done before and, therefore, is considered unique. As the product of each project is unique, peculiar characteristics that distinguish it must be progressively elaborated (PMI, 2017). If properly used, project management can support the control of all project stages, allowing the achievement of pre-established objectives and the improvement of activities via lessons learned (Kerzner, 2017). Consequently, improvements in reliability, quality and flexibility will occur over time, increasing the competitiveness of companies and improving their image in the market (Butler et al., 2018).

Currently, the knowledge and practices associated with project management are grouped into knowledge areas. These areas may vary depending on the organization that disseminates the guidelines, but in general, the general content is similar. As an example, the ten areas of the PMBOK are: Integration; Scope; Schedule; Cost; Quality; Resources, Procurement, Risk, Communications; Stakeholders (PMI, 2017). Projects must reach their objectives, achieving 
success. In older conceptions, success in project management was linked to the efficient control of costs, deadline, scope and quality, but over time, it was verified that monitoring these items was not enough (Carvalho et al., 2015; Todorović et al., 2015).

Achieving success in project management requires constancy of purpose and spirit of continuous improvement and, in this sense, the project manager has a fundamental role in leading the team (ISO, 2012; Sankaran et al., 2019). It is necessary to understand each difficulty that arises during the process, work to reduce or eliminate it and use the lessons learned in future projects, as mentioned by Kerzner (2017).

It should be noted that lessons learned in certain sectors can be used even in others, and this exchange of information is synergistic for the evolution of all companies. Of course, some sectors are better explored by the academic literature on project management, such as the automotive sector, aerospace, construction, while others are less debated, such as the nuclear sector focused by Saunders and Townsend (2019). In this research, the authors analyzed the challenges observed in three nuclear plants projects in the United Kingdom and, based on this analysis, they proposed plausible guidelines to be used in different types of megaprojects. Saunders and Townsend (2019) and Mainga (2017) argue that difficulties observed in project management in different sectors are characterized as valuable sources of information and learning. In addition to being challenges during projects planning and execution, these difficulties can cause projects failure (Ika et al., 2020; Lalmi et al., 2021; Sage et al., 2014).

Projects beginning presents many difficulties according to the literature. Some authors (Iyer and Banerjee, 2016; Khamooshi and Golafshani, 2014; Martinsuo and Hoverfält, 2018) highlight the difficulty of managers to correctly define the scope of projects since many factors are not properly described in the planning stage. In other studies (Butt et al., 2016; Lu and Wang, 2017; Oliveira et al., 2018), authors argue that many managers have difficulties understanding who the stakeholders and their interests are, thus compromising activities throughout the project. The need to change project scope a posteriori requires to rework can cause several delays (Iyer and Banerjee, 2016; Martinsuo and Hoverfält, 2018; Tomotani and de Mesquita, 2018) and additional costs (Ahsan and Gunawan, 2010).

Difficulties are also observed when managers partition the scope into specific objectives to be achieved by teams (Khamooshi and Golafshani, 2014; Martinsuo and Hoverfält, 2018; Tomotani and de Mesquita, 2018; Yaghootkar and Gil, 2012). Scope, strategies and objectives must remain consistent among different areas and hierarchical levels (Corrêa et al., 2018). During the project execution, activities need to be prioritized, due to resources constraint (Bryde et al., 2018; Love et al., 2018; Martinsuo and Hoverfält, 2018). In addition, it is 
important to allocate responsibilities for team members (Love et al., 2018; Matthews et al., 2018; Wu et al., 2017). In general, difficulties are observed in these stages, and a great potential for improvements can be verified.

It is necessary to support the team throughout the project, keeping its synergy with the project scope; a good communication flow is particularly important for this. Unfortunately, many managers still have difficulties integrating team and keep a good communication flow (Demirkesen and Ozorhon, 2017; Keegan et al., 2017; Suprapto et al., 2015). It is part of every project management to manage risks. However, several managers have difficulty conducting this properly measure and deal with risks (Shi et al., 2015; Zhao and Cao, 2015; Zwikael et al., 2014). De Paula et al. (De Paula et al., 2019) highlight that project managers need to expand the use of quantitative tools for projects' risk management.

The correct structuring of the project schedule requires attention. However, many managers accelerate this activity in the planning phase to begin the execution phase; consequently, difficulties related to deadlines are evidenced throughout the project (Love et al., 2018; Myrelid, 2017; Tomotani and de Mesquita, 2018).

In specific sectors, projects conducted by companies demand attention in technical knowledge management, e.g., some projects of engineering companies require greater participation from partners and suppliers. Difficulties to manage technical knowledge (Martinsuo and Hoverfält, 2018; Oliveira et al., 2018; Wu et al., 2017) and difficulty in managing suppliers and other partners (Mu et al., 2014; Oliveira et al., 2018) are highlighted in the literature.

Whenever there are deviations in activities initially outlined, actions are required and additional costs are usually demanded. Difficulties in the management of financial resources are mentioned by many authors as a challenge to be overcome in project management (Butler et al., 2018; Lin et al., 2015; Martinsuo and Hoverfält, 2018; Mu et al., 2014; Sanchez et al., 2017).

Many of the activities mentioned above may be facilitated through the use of software and tools that support decision-making. However, some authors argue that many managers do not use them and often have difficulties in understanding how they can be used to support the management (Haverila and Fehr, 2016; Johansen and Rolstadås, 2017; Love et al., 2018; Matthews et al., 2018).

The difficulties observed in projects of hydroelectric turbines can be considered a few explored topic in the literature, that belongs to a sector also few explored: metalmechanic sector. In addition, the considered projects are interesting cases to the project 
management field and can motivate debates to improve techniques and tools of the area, since they present singular characteristics. The manufacturing of large "mechanical sets", as it is the case of hydroelectric turbines, demands careful management of dimensional tolerances among different companies, uses gigantic manufacturing equipment, requires hiring third parties to provide specialized services in customized parts, among other factors that make management complex.

Based on the context presented, this study aims to analyze the difficulties observed in the management of three hydroelectric turbine projects developed by a company in the metalmechanic segment. This analysis will be performed through case studies. In addition, content analysis and Grey Relational Analysis (GRA) will be used as techniques to analyzed data. We understand that studying the difficulties related to hydroelectric turbines projects management, we are investigating the constraints that do not allow these projects management to reach better results. The information presents here may contribute to the expansion of debates on project management in a segment few explored by academic literature.

\section{Methodological procedures}

For the development of this study, five stages were established: 1) bibliographic research to better understand aspects and difficulties associated with project management; 2) elaboration of the protocol to be used in data collection; 3) case studies development; 4) content analysis of the data collected according to Elo and Kyngäs (2008) guidelines and Grey Relational Analysis based on Kuo et al. (2008) and; 5) debates of the results and conclusions establishment.

In the first stage, bibliographic research had an emphasis on difficulties observed in project management mentioned in articles published in relevant journals. The bases consulted were Emerald Insight, Science Direct, Taylor \& Francis, Scopus and publications from the Project Management Institute. The search terms used were "project", associated with the descriptors "management", "time", "integration", "scope", "cost", "quality", "communication", "risk", “acquisitions", "resources", "stakeholders", “difficulties". More specifically, the terms cited were combined with the term "hydroelectric turbines". From the search, it was possible to obtain the difficulties presented in Table 1.

Table 1 position. 
Based on the difficulties presented in Table 1, which were for project management in general, the protocol to be used in the three case studies was structured (stage 2), to focus on hydroelectric turbines projects. Projects on the company are selected due to their different technical characteristics and the complexity of the contractual relationship. According to Yin (Yin, 2014), the case study is characterized by an analysis of one or more objects, to allow detailed knowledge about a problem not sufficiently defined. Multiple sources of evidence were used in this study (semi-structured interviews, document analysis, direct observations and visits to the company) to better understand the three-case studies context. For Yin (2014), the use of several sources of evidence, named triangulation, allows better support of the propositions.

Focusing on the semi-structured interviews, managers who coordinate the projects firstly discussed each difficulty presented in Table 1 and, in the sequence, measured a grade from 0 to 10 , in which 0 meant "difficulty not observed" and 10 meant "difficulty extremely observed". Before data collection, the research project was submitted to the appreciation of a Research Ethics Committee and approved.

For case studies development (stage 3), initial contact was established with the general manager of the company who directed the researchers to the managers interviewed, respecting the diversity of projects desired in the study. Visits were scheduled for the case studies development. The company analyzed operates in the global market, supplying components for hydroelectric power plants. Its products and services portfolio covers the entire life cycle of small and large hydroelectric plants (generators, turbines, pumps, electromechanical components, automation systems, measurement, regulation and control systems). It also provides maintenance services and operates in the spare parts market. It is part of a larger group that operates in other essential cores: energy, oil and gas, paper, raw materials, transportation and automotive.

The projects selected to conduct the case studies were chosen due to their different technical characteristics and contractual relationship complexity. Regarding the technical characteristics, projects with different quantities of energy generating units were analyzed. For projects not yet finalized regarding the all-contracted units, the analysis was performed considering only units received by customers, allowing a complete investigation of the products. Regarding contractual relationship complexity, intercompany or consortium projects were analyzed, which requires the relationship with partners in different cultural contexts. It should be highlighted that although the analysed projects presented difficulties (studied in this research), these projects achieved their goals. Logically, some of the observed difficulties were 
overcome through the use of additional resources, besides those initially planned, that enabled goals' achievement on time.

In stage 4, qualitative data collected in semi-structured interviews, documentary analysis and observation in visits performed ) were analyzed through content analysis according to Elo and Kyngäs (2008) guidelines. Quantitative data collected in semi-structured interviews (scores from 0 to 10) were analysed comparatively through Grey Relational Analysis (GRA) according to Kuo et al. (2008) guidelines.

Content analysis is a systematic and objective method to describe and quantify a phenomenon (Sandelowski, 1995). It is a research method to analyse data in a context, providing knowledge, new ideas, facts representation or practical action guide (Bardin, 2011; Krippendorff, 1980). It may be used to develop an understanding of a phenomenon (Cavanagh, 1997) and for critical processes identification (Lederman, 1991). Content analysis is a technique largely used to investigate data from interviews (Elo and Kyngäs, 2008).

The content analysis carried out in this study uses the guidelines proposed Elo and Kyngäs (2008), applied in different fields of knowledge. The deductive method of analysis was chosen because we have pre-defined difficulties to conduct the analysis (difficulties presented in Table 1). The following phases were carried out: document preparation phase (transcriptions of the interviews and organization of other information collected), familiarization phase to better understand the context, analysis of the information considering coding for difficulties, comparisons, presentation of entire analysis process and establishment of general overview (adapted from (Elo and Kyngäs, 2008)). According to Elo and Kyngäs (2008) it is important to describe all the steps performed and highlight the limitations of the study. The detailed description done in this section has this purpose.

Regarding the quantitative data (scores from 0 to 10), they were analyzed via Grey Relational Analysis (GRA) according to Kuo et al. (2008) guidelines, aiming to establish a comparative ranking of the difficulties. An interesting feature of this index is that it considers uncertainties associated with the data and, thus, generates more robust results. The use of GRA is adequate when analysed data may vary due to respondents' perceptions and knowledge level. This is the case of this study, thus, GRA is an adequate technique for the kind of data collected and for the study main goal: to rank the difficulties.

According to Kuo et al. (2008) GRA is developed in 4 steps: 1) construction of Grey Relational Generating (GRG), 2) target sequence definition, 3) Grey Relational Coefficients 
(GRC) assessment and, finally, 4) Grey Relational Grade (R) assessment. An interesting application of this analysis may be seen in the study of Satolo et al. (2018).

Firstly, the data matrix is structured considering scores measures for managers for each difficulty. In the sequence, the mentioned matrix is normalized according to Equation 1 and the GRG matrix is obtained (Kuo et al., 2008). The equation for "the-largest-the-better attributes" was used to allocate the most intense difficulty in the first position of the ranking. According to Kuo et al. (2008), the researcher needs to correctly define how to normalize the data and correctly interpret the results generated.

$$
\left.X i j=\frac{Y i j-\operatorname{Min}\{\mathrm{Yij}, i=1,2, \ldots, m\}}{\operatorname{Max}\{Y i j, i=1,2 \ldots, m\}-\operatorname{Min}\{Y i j, i=1,2 \ldots, m\}} \quad \text { for } i=1,2, \ldots, m \quad j=1,2, \ldots, n \text { (Equation } 1\right)
$$

The second step consisted of calculating the difference of each GRG matrix element for the reference sequence, using Equation 2. In this equation, $X_{0 j}=1$ and $X_{i j}$ represents each GRG matrix element.

$$
\Delta_{i j}=X_{0 j}-X_{i j} \quad(\text { Equation } 2)
$$

Then, the Grey Relational Coefficient is calculated ( $(\varepsilon)$ through Equation 3. In this study, we decided to use " 1 " as reference (in $\mathrm{X}_{0 \mathrm{j}}$ ) and distinguishing coefficient $(\rho)$ equal to 0.5 . The values of $\Delta_{\max }$ and $\Delta_{\min }$ are calculated considering the values resulting in step 2; $\Delta_{\mathrm{ij}}$, in turn, is calculated using Equation 2.

$$
\varepsilon_{i j}=\frac{\Delta_{\min }+\rho \times \Delta_{\max }}{\Delta_{i j}+\rho \times \Delta_{\max }} \quad(\text { Equation } 3)
$$

Finally, the Grey Relational Grade (R) is calculated. In this study, different weightings to analyzed projects were not assigned. Then, the value corresponds to the average of the values obtained from the Grey Relational Coefficient $(\varepsilon)$, according to Equation 4.

$$
R=\frac{1}{n} \sum_{k=1}^{n} \varepsilon_{i}(k) \quad(\text { Equation } 4)
$$

With $\mathrm{R}$ values, it was possible to rank the difficulties comparatively and discuss the results. 


\section{Results and associated debates}

\subsection{Description of the projects chosen for the case studies}

The projects in the analysed company were classified by size according to the kind of product they develop and produced and the specificities of the projects. The interviews to collect data about each project were conducted with project managers responsible for them.

Project 1 was associated with the development and manufacture of six power generating units for a plant installed in Canada. This project was classified as an intercompany project since the Brazilian company was sub-contracted by another company. This company negotiated with the customer. It was a large project and it was concluded when this research was performed. The manager responsible for this project had 5 years of experience as a manager and he does not have a team full-time dedicated to the project, but four managers (and their teams) to support project development.

Project 2 was associated with the development and manufacture of four power generating units for a plant installed in the United States. The company developed and manufactured all the components of the generating units and the contractual relations also were classified as intercompany. Regarding size, the project was classified as medium-sized and it was concluded when this research was performed. In this project, the manager had 12 years of experience and count with a support team composed of four managers and their teams to support the project's development, but not fully dedicated to it.

Project 3 was associated with the development and manufacture of ten power generating units for a plant installed in Brazil. The company operates in this project in a consortium, supplying various components of turbines and generators. The project was classified as large and it was concluded when this research was performed. The manager of this project had 23 years of experience and an entire team was dedicated to the project development.

\subsection{Difficulties observed in the studied projects: a comparative analysis}

Based on the results of content analysis, information was obtained about each project and a cross-analysis was performed to identifying convergences and divergences among projects. The next paragraphs will present information regarding each difficulty present in Table 1 and Figure 1 will show scores measured by managers.

Teams integration and the maintenance of effective communication were evidenced as intense difficulty in hydroelectric turbine projects (scores $10 ; 8 ; 7$ ). The three managers 
highlighted that many of these difficulties were associated with issues related to cultural factors (when involves companies from different countries), metric performance system used by companies and different types of team's dedication to the project.

Difficulty in allocating human resources and defining responsibilities for team members was not intensively highlighted by the managers in the analysed projects (scores $3 ; 2 ; 3$ ). There was only a mention that they encountered difficulties in management aspects related when unplanned activities arise and require additional resources. The literature on project management points out variations of project team members (Al-jibouri, 2002; Vilventhan and Kalidindi, 2018; Yang et al., 2014; Yng et al., 2018), unplanned activities (Keegan et al., 2017), difficulty in finding specialized professionals (Kissi et al., 2013; Matthews et al., 2018) and difficulty in aligning deadlines and priorities (Love et al., 2018) as the main causes related to the difficulty in allocating human resources and defining responsibilities.

Continuing, the results of the content analysis showed that managers pointed out as medium difficulty the definition of project scope and the need to make changes in it when necessary (D4) (scores 5; 7; 5). The literature on project management points out some causes to this: difficulty in defining stakeholders interests (Martinsuo and Hoverfält, 2018), lack of verifications in project scope (Iyer and Banerjee, 2016), difficulty to define real objectives (Soja, 2010), and difficulty to understand requirements (Odasso et al., 1996). The manager highlighted that changes in the scope of hydroelectric turbine projects are complicated because they normally demand changes in costs, deadlines and human resources allocation. Sometimes, this may provide rework and cause dissatisfaction of some stakeholders, as mentioned by Khamooshi and Golafshani (Khamooshi and Golafshani, 2014).

For technical knowledge management (D5), managers consider the difficulties in a lowintensity level, however, there was a considerable discrepancy among scores $(0 ; 1 ; 4)$. The managers mentioned that this difficulty is related to hydroelectric turbine projects (influencing the type of turbine produced or repaired, the qualification of professionals allocated, among other characteristics). The literature on project management shows that difficulties in the management of technical knowledge may be related to: lack of specific skills or knowledge to carry out the activities (Sisirakumara and Choy, 2018; Yang et al., 2014), poor qualification of professionals allocated on the project (Zhang and Li, 2016), difficulty in disseminating knowledge (Godfrey et al., 2018; Haverila and Fehr, 2016; Hui and Martin, 2020; Oliveira et al., 2018) and delays related to management aspects (Antony et al., 2012; Sajid and Usman, 2019; Wu et al., 2017). 
Regarding the difficulties of using software and tools to support decision making (D6), managers considered this difficulty with a low-intensity level (scores 3;0;3). Managers reported some difficulties in using tools to decide customer requirements or priorities activities defining, for example. Some of the aspects mentioned by literature and presented in the previous paragraph also may be cited as causes of this difficulty: lack of specific skills or knowledge to carry out the activity (Matthews et al., 2018), poor qualification of the professionals assigned to the project (Johansen and Rolstadås, 2017), difficulty in disseminating knowledge (Godfrey et al., 2018; Haverila and Fehr, 2016; Hui and Martin, 2020; Oliveira et al., 2018).

Regarding the difficulty in structuring and managing schedule (D7), the managers showed different degrees of intensity (small for project 1, large for project 2 and medium for project 3 . - respectively, scores 3; 9; 5). Manager 2 argued that the planned schedule for project 2 did not consider the time for certain critical activities and this compromised its management. As a result, it was necessary to involve more professionals who were not initially expected in some stages and to review the project documentation.

The difficulty in managing financial resources (D8) was considered low intensity by managers of projects 2 and 3 and high intensity by the manager of project 1 (scores $8 ; 2 ; 3$ ). There were many cost reviews in project 1; to project continuity, it was necessary extra resources. According to the literature on project management, difficulties in managing financial resources may be related to: difficulty in realistically estimate activities (Butler et al., 2018; Engwall and Jerbrant, 2003; Osei-Kyei and Chan, 2015) and difficulty in dealing with changes on planning (Atkinson, 1999; Fossum et al., 2019; Martinsuo and Hoverfält, 2018; Zhao and Cao, 2015).

Regarding the difficulty in managing risks (D9), project manager 2 mentioned that this difficulty was not observed in his project; the manager responsible for project 3 pointed out a low-intensity level to the mentioned difficulty; manager 1 evidenced a higher difficulty in managing risks in hydroelectric turbines project (scores $6 ; 0 ; 3)$. Manager 1 the need to deal with an unevaluated risk and that this demanded extra time and impacted other areas. The difficulty in controlling risks of the project is mention by many authors (Boateng et al., 2015; Christopher and Leon, 2019; Cigolini and Rossi, 2010; Hwang et al., 2014; Zhao and Cao, 2015; Zwikael et al., 2014).

For the management of suppliers and other partners (D10), the intensities associated with this difficulty were allocated between medium and high intensity (scores $6 ; 5 ; 8$ ). Difficulty in managing project stakeholders (D11) was also characterized between medium and high 
intensity (score 7; 7;6); managers pointed out difficulties in dealing with the discontent stakeholders, especially the company's board.

Finally, regarding the difficulty in defining and prioritizing activities (D12), scores varied a lot (medium intensity for project 1, low intensity for project 2 and from medium to high intensity for project 3 - scores 4;1;7 respectively). According to managers of projects 1 and 3, the difficulty in establishing priority activities occurred when delivery times became critical. Among the possible reasons for this difficulty, it can be mentioned: lack of flexibility (Ahsan and Gunawan, 2010), difficulties in dealing with changes (Yang et al., 2014), and poor scope definition (Iyer and Banerjee, 2016).

The scores attributed by the manager of each project for each analyzed difficulty are summarized in Figure 1.

\section{Figure 1 position.}

The analyzed projects are unique and have different characteristics. In order to obtain a unique comparative ranking of the difficulties analyzed in the management of hydroelectric turbine projects, a Grey Relational Analysis (GRA) was performed according to Kuo et al. (2008) guidelines. The scores were normalized, using Equation 1, and the values obtained (Grey

Relational Generating) are shown in Table 2. To exemplify how Table 2 was developed, the calculation of the normalized value for D1 in project 1 is presented.

$$
X_{11}=\frac{7-1}{10-1}=\frac{6}{9}=0.667 \quad \text { (Example of Equation } 1 \text { application) }
$$

Table 2 position.

The reference was defined as "1" in the Equation 2, it was possible to calculate the difference of each element of Table 2 for it. These values are presented in Table 3.

\section{Table 3 position.}

Considering values of Table 3 and using Equation 3, it was possible to calculate the Grey Relational Coefficients for each manager and each difficulty. As equal weightings were established for the three hydraulic turbine projects analyzed, the Grey Relational Grade for each 
difficulty is given by the average of the observed values (R) (Equation 4) (Table 4). Grey Relational Grade values were used to order comparatively the difficulties, as shown in Table 5.

\section{Table 4 position.}

\section{Table 5 position.}

When analyzed the difficulties comparatively, five of them stand out. It can be observed, initially, that the difficulties related to "integration and communication among the teams working on the project" have the greatest intensity, comparatively. Its Grey Relational Grade is higher than other difficulties. Difficulties in communication often hinder better integration among teams involved this prevents the achievement of better results (Hui and Martin, 2020; Ollus et al., 2011). In the second position, there is difficulty in managing suppliers and other partners. It is possible to observe that these two difficulties are related to hydroelectric turbine project characteristics, which in general involve several teams, sometimes from different companies and nationalities and require the supply of different types of mechanical parts and specialized services. Problems to manage relationships with suppliers, such as mentioned by some authors (Mu et al., 2014; Myrelid, 2017). These authors also argue that good management of partners and suppliers is an essential factor for projects to achieve their goals and succeed.

Considering possible sensitivity variations in the results, difficulties D1 (Difficulty in defining objectives and partition of them for teams), D11 (Difficulty in managing project stakeholders), D7 (Difficulty in structuring and managing of the schedule) form an intermediate block that also, comparatively, stand out from the subsequent difficulties. Regarding the goals, some authors (Lu and Wang, 2017; Martinsuo and Hoverfält, 2018; Tomotani and de Mesquita, 2018) argue that it is necessary to be clear for teams involved in the project what part of the project belongs to them, to avoid misunderstandings and problems to reach the goals. Regarding stakeholders management, it is stated in the literature (Chika et al., 2019; Jing et al., 2018; Lu and Wang, 2017; Oliveira et al., 2018; Yahaya and Qiping, 2020) that it is important to identify all stakeholders of the project and properly understand their demands, to reach a balanced scope. The failure to complete this phase or misunderstanding the demands of each stakeholder can cause problems for the project. Finally, regarding the schedule, some authors (Keegan et al., 2017; Love et al., 2018; Martinsuo and Hoverfält, 2018; Myrelid, 2017; Tomotani and de Mesquita, 2018; Wu et al., 2017) emphasize the importance of managers properly debating the 
time and resources allocated to each activity and critically analyzing the feasibility of complying with the schedule while still in the planning phase

Specifically regarding D3 (Difficulty in allocating human resources and defining responsibilities for team members), according to the kind of project, the human resources allocation can be a great challenge, since projects often require skills that are not developed or present in the work team (Bryde et al., 2018; Iyer and Banerjee, 2016; Keegan et al., 2017; Martinsuo and Hoverfält, 2018; Yng et al., 2018). Especially when it is considered the hydroelectric turbines, the teams work on projects for these mechanical sets for some time, so it is not difficult to allocate human resources to these activities, as is often presented in other works.

\section{Conclusions and Final Considerations}

As previously mentioned, the segment of companies that produce hydroelectric turbines is characterized as a field few explored by academic research in project management. This study aimed to analyze the difficulties observed by managers in three projects developed by a company of the mentioned sector and, considering the results presented, it is possible to say that the main objective was achieved.

From the twelve difficulties analysed, five of them stood out: the difficulty of integration and communication; difficulty in managing suppliers and other partners; difficulty in defining objectives and partition of them for teams; difficulty in managing project stakeholders, and difficulty in structuring and managing the schedule. The first and second difficulties mentioned are related to the type of hydroelectric turbines project conducted. This kind of project, in general, involves many teams from different companies and supply of diverse mechanical parts and services. These five difficulties most evidenced, through GRA analysis, can be understood as those comparatively most critics. If they are not properly managed, the initial planning structured for the project can be compromised, demanding additional resources of different kinds to reach the proposed goals or even preventing the project to succeed.

The managers responsible for the hydroelectric turbines' projects need to value the lessons learned throughout the process since these lessons present important knowledge for continuously improving managers work. Generally, as soon as a hydroelectric turbine is delivered to the customer, little or nothing is debated about observed difficulties. All the knowledge generated from projects difficulties should be widely debated and reflected by the 
company's professionals, in order to enable them to understand difficulties' causes and to proactively act in future projects.

Regarding the implications of this study, we highlight the contributions mainly for professionals who work in the management of hydroelectric turbines projects and researchers interested in the area. The managers of these segments, aware in advance of the main difficulties reported here, will be able to devote more attention to certain points in the conduction of projects they manage and take corrective actions before the problems become greater. Concerning research in the management field, academics can use these difficulties as guidelines to develop tools and techniques that enable better results in terms of management. In our study, for example, the difficulty of integration and communication was shown to be the most critical comparatively. The development of tools that support a more effective exchange of information between teams that work on a project can be of great value.

As a limitation of the research, the fact that the selected case studies belong to a single company may be cited. However, the projects diversity is emphasized, since they contemplate different characteristics in the analysis. The case studies collected data via visits, semistructured interviews and others document and data analysis was performed considering qualitative and quantitative aspects. It is suggested, as future studies, to carry out research to analyze in detail the difficulties highlighted here, such as the question of integration and communication.

Note: A preliminary and summarized version of this article was presented in Portuguese at the VIII SIGEP, a Brazilian event. The version presented here corresponds to an expanded version, including new information and analysis.

\section{References}

Ahsan, K. and Gunawan, I. (2010), “Analysis of cost and schedule performance of international development projects", International Journal of Project Management, Vol. 28 No. 1, pp. $68-78$.

Al-jibouri, S. (2002), "Effects of resource management regimes on project schedule", International Journal of Project Management, Pergamon, Vol. 20 No. 4, pp. 271-277.

Aleksic, A., Puskaric, H., Tadic, D. and Stefanovic, M. (2017), "Project management issues: vulnerability management assessment”, Kybernetes, Vol. 46 No. 7, pp. 1171-1188.

Anholon, R. and Sano, A.T. (2016), “Analysis of critical processes in the implementation of 
lean manufacturing projects using project management guidelines", The International Journal of Advanced Manufacturing Technology, Vol. 84 No. 9-12, pp. 2247-2256.

Antony, J., Gijo, E.V. and Childe, S.J. (2012), "Case study in Six Sigma methodology: manufacturing quality improvement and guidance for managers", Production Planning \& Control, Vol. 23 No. 8, pp. 624-640.

Atkinson, R. (1999), "Project management: cost, time and quality, two best guesses and a phenomenon, its time to accept other success criteria", International Journal of Project Management, Pergamon, Vol. 17 No. 6, pp. 337-342.

Bardin, L. (2011), Análise de Conteúdo, Revista Educação, Vol. 1, EDIÇOES 70 - BRASIL, São Paulo, available at:https://doi.org/10.1017/CBO9781107415324.004.

Boateng, P., Chen, Z. and Ogunlana, S.O. (2015), “An Analytical Network Process model for risks prioritisation in megaprojects", International Journal of Project Management, Elsevier Ltd, Vol. 33 No. 8, pp. 1795-1811.

Bryde, D., Unterhitzenberger, C. and Joby, R. (2018), “Conditions of success for earned value analysis in projects", available at:https://doi.org/10.1016/j.ijproman.2017.12.002.

Butler, M., Szwejczewski, M. and Sweeney, M. (2018), “A model of continuous improvement programme management", Production Planning \& Control, pp. 1-17.

Butt, A., Naaranoja, M. and Savolainen, J. (2016), "Project change stakeholder communication", International Journal of Project Management, Pergamon, Vol. 34 No. 8, pp. 1579-1595.

Carvalho, M.M. de, Patah, L.A. and de Souza Bido, D. (2015), "Project management and its effects on project success: Cross-country and cross-industry comparisons", International Journal of Project Management, Pergamon, Vol. 33 No. 7, pp. 1509-1522.

Cavanagh, S. (1997), "Content analysis: concepts, methods and applications", Nurse Researcher, Vol. 4 No. 3, pp. 5-16.

Chika, A., Pat, C. and Martin, T. (2019), "PPP projects: improvements in stakeholder management", Engineering, Construction and Architectural Management, Emerald Publishing Limited, Vol. 27 No. 2, pp. 544-560.

Christopher, A. and Leon, P. (2019), "Evaluation of the impact of risk management on project performance in small construction firms in South Africa: The case study of construction systems", Journal of Engineering, Design and Technology, Emerald Publishing Limited, Vol. 18 No. 3, pp. 611-634.

Cigolini, R. and Rossi, T. (2010), "Managing operational risks along the oil supply chain", Production Planning \& Control, Vol. 21 No. 5, pp. 452-467. 
Corrêa, H.L., Gianesi, I.G.N. and Caon, M. (2018), Planejamento, Programação e Controle Da Produção - MRP II / ERP, edited by Atlas, 6ed ed., São Paulo.

Demirkesen, S. and Ozorhon, B. (2017), "Impact of integration management on construction project management performance", International Journal of Project Management, Pergamon, Vol. 35 No. 8, pp. 1639-1654.

Elo, S. and Kyngäs, H. (2008), “The qualitative content analysis process”, Journal of Advanced Nursing, Vol. 62 No. 1, pp. 107-115.

Engwall, M. and Jerbrant, A. (2003), "The resource allocation syndrome: the prime challenge of multi-project management?", International Journal of Project Management, Vol. 21 No. 6, pp. 403-409.

Fossum, K.R., Binder, J.C., Madsen, T.K., Aarseth, W. and Andersen, B. (2019), "Success factors in global project management", International Journal of Managing Projects in Business, Emerald Publishing Limited, Vol. 13 No. 1, pp. 128-152.

Godfrey, O.E., Omaruaye, O.O., Tarila, Z., Raymond, A., Wilfred, M., Ximing, R. and Akunna, O. (2018), "Utilising a systematic knowledge management based system to optimise project management operations in oil and gas organisations", Information Technology \& People, Emerald Publishing Limited, Vol. 31 No. 2, pp. 527-556.

Haverila, M.J. and Fehr, K. (2016), "The impact of product superiority on customer satisfaction in project management", International Journal of Project Management, Elsevier Ltd and Association for Project Management and the International Project Management Association, Vol. 34 No. 4, pp. 570-583.

Hui, Y.J.B. and Martin, S. (2020), "Ameliorating time and cost control with project learning and communication management: Leveraging on reusable knowledge assets", International Journal of Managing Projects in Business, Emerald Publishing Limited, Vol. 13 No. 4, pp. 767-792.

Hwang, B.-G., Zhao, X. and Toh, L.P. (2014), "Risk management in small construction projects in Singapore: Status, barriers and impact", International Journal of Project Management, Pergamon, Vol. 32 No. 1, pp. 116-124.

Ika, L.A., Söderlund, J., Munro, L.T. and Landoni, P. (2020), “Cross-learning between project management and international development: Analysis and research agenda", International Journal of Project Management, Vol. 38 No. 8, pp. 548-558.

ISO. (2012), "ISO-21500 Guidance on project”, International Organization for Standardization.

Iyer, K.C. and Banerjee, P.S. (2016), "Measuring and benchmarking managerial efficiency of project execution schedule performance", International Journal of Project Management, 
Pergamon, Vol. 34 No. 2, pp. 219-236.

Jing, Y.R., Sajani, J., Chathuri, G., Mehrdad, A., Xiaolong, X. and Guomin, Z. (2018), "The evolution of stakeholder management practices in Australian mega construction projects", Engineering, Construction and Architectural Management, Emerald Publishing Limited, Vol. 25 No. 6, pp. 690-706.

Johansen, A. and Rolstadås, A. (2017), "Decision process in one-of-a-kind production", Production Planning \& Control, Taylor \& Francis, Vol. 28 No. 10, pp. 802-812.

Keegan, A., Ringhofer, C. and Huemann, M. (2017), "Human resource management and project based organizing: Fertile ground, missed opportunities and prospects for closer connections”, International Journal of Project Management, Vol. 36, pp. 121-133.

Kerzner, H. (2017), Project Management: A Systems Approach to Planning, Scheduling and Controlling, 12 ed., John Wiley \& Sons, Hoboken:

Khamooshi, H. and Golafshani, H. (2014), "EDM: Earned Duration Management, a new approach to schedule performance management and measurement", International Journal of Project Management, Pergamon, Vol. 32 No. 6, pp. 1019-1041.

Kissi, J., Dainty, A. and Tuuli, M. (2013), "Examining the role of transformational leadership of portfolio managers in project performance", International Journal of Project Management, available at:https://doi.org/10.1016/j.ijproman.2012.09.004.

Krippendorff, K. (1980), Content Analysis an Introduction to Its Methodology, London.

Kuo, Y., Yang, T. and Huang, G.-W. (2008), “The use of grey relational analysis in solving multiple attribute decision-making problems", Computers \& Industrial Engineering, Vol. 55 No. 1, pp. 80-93.

Lalmi, A., Fernandes, G. and Souad, S.B. (2021), “A conceptual hybrid project management model for construction projects”, Procedia Computer Science, Vol. 181, pp. 921-930.

Lederman, R.P. (1991), "Quantitative and Qualitative Research Methods: Advantages of Complementary Usage", MCN, The American Journal of Maternal/Child Nursing, Vol. 16 No. 1, p. 43.

Lin, T.-C., Chen, C.-M., Hsu, J.S.-C. and Fu, T.-W. (2015), “The impact of team knowledge on problem solving competence in information systems development team", International Journal of Project Management, Pergamon, Vol. 33 No. 8, pp. 1692-1703.

Love, P.E.D., Teo, P., Ackermann, F., Smith, J., Alexander, J., Palaneeswaran, E. and Morrison, J. (2018), "Reduce rework, improve safety: an empirical inquiry into the precursors to error in construction", Production Planning \& Control, pp. 1-14.

Lu, W. and Wang, J. (2017), “The influence of conflict management styles on relationship 
quality: The moderating effect of the level of task conflict", International Journal of Project Management, available at:https://doi.org/10.1016/j.ijproman.2017.08.012.

Mainga, W. (2017), “Examining project learning, project management competencies, and project efficiency in project-based firms (PBFs)", International Journal of Managing Projects in Business, Vol. 10 No. 3, pp. 454-504.

Martinsuo, M. and Hoverfält, P. (2018), "Change program management: Toward a capability for managing value-oriented, integrated multi-project change in its context", International Journal of Project Management, Elsevier Ltd, Vol. 36 No. 1, pp. 134-146.

Matthews, J., Love, P.E.D., Mewburn, J., Stobaus, C. and Ramanayaka, C. (2018), "Building information modelling in construction: insights from collaboration and change management perspectives", Production Planning \& Control, Vol. 29 No. 3, pp. 202-216.

Mu, S., Cheng, H., Chohr, M. and Peng, W. (2014), “Assessing risk management capability of contractors in subway projects in mainland China", International Journal of Project Management, Pergamon, Vol. 32 No. 3, pp. 452-460.

Myrelid, P. (2017), "Information quality deficiencies in delivery schedules and their impact on production scheduling", Production Planning \& Control, Taylor \& Francis, Vol. 28 No. 3, pp. 232-243.

Odasso, A., Bitton, M., Corti, M., Doumeingts, G., McMullin, J. and Regnier, P. (1996), "Managing change in manufacturing organizations", Production Planning and Control, Taylor \& Francis Group, Vol. 7 No. 6, pp. 594-603.

Oliveira, E.C.B. de, Alencar, L.H. and Costa, A.P.C.S. (2018), "Decision process of allocating projects to project managers", Production Planning \& Control, pp. 1-10.

Ollus, M., Jansson, K., Karvonen, I., Uoti, M. and Riikonen, H. (2011), "Supporting collaborative project management”, Production Planning and Control, Vol. 22 No. 5-6, pp. 538-553.

Osei-Kyei, R. and Chan, A.P.C. (2015), "Review of studies on the Critical Success Factors for Public-Private Partnership (PPP) projects from 1990 to 2013", International Journal of Project Management, Pergamon, Vol. 33 No. 6, pp. 1335-1346.

De Paula, C.P., Cordeiro, G.A., Rampasso, I.S., Ordoñez, R.E.C. and Anholon, R. (2019), “Métodos Quantitativos para Gestão de Risco em Projetos: Uma Revisão da Literatura", Revista Gestão Da Produção Operações e Sistemas, Vol. 14 No. 2, pp. 129-148.

PMI. (2017), A Guide to the Project Management Body of Knowledge (PMBOK Guide). 6th, 6th Editio., Project Management Institute, Inc., New York.

Saeed, M.A., Jiao, Y., Zahid, M.M., Tabassum, H. and Nauman, S. (2020), “Organizational 
flexibility and project portfolio performance: the roles of innovation, absorptive capacity and environmental dynamism", International Journal of Managing Projects in Business, Vol. ahead-of-p No. ahead-of-print, available at:https://doi.org/10.1108/IJMPB-02-20200058 .

Sage, D., Dainty, A. and Brookes, N. (2014), "A critical argument in favor of theoretical pluralism: Project failure and the many and varied limitations of project management", International Journal of Project Management, Vol. 32 No. 4, pp. 544-555.

Sajid, K.M. and Usman, M. (2019), "Management competencies, complexities and performance in engineering infrastructure projects of Pakistan", Engineering, Construction and Architectural Management, Emerald Publishing Limited, Vol. 26 No. 7, pp. 1321-1347.

Sanchez, O.P., Terlizzi, M.A. and de Moraes, H.R. de O.C. (2017), "Cost and time project management success factors for information systems development projects", International Journal of Project Management, Elsevier Ltd and Association for Project Management and the International Project Management Association, Vol. 35 No. 8, pp. 1608-1626.

Sandelowski, M. (1995), "Qualitative analysis: What it is and how to begin", Research in Nursing \& Health, Vol. 18 No. 4, pp. 371-375.

Sankaran, S., Vaagaasar, A.L. and Bekker, M.C. (2019), “Assignment of project team members to projects", International Journal of Managing Projects in Business, Vol. 13 No. 6, pp. 1381-1402.

Satolo, E.G., Leite, C., Calado, R.D., Goes, G.A. and Salgado, D.D. (2018), "Ranking lean tools for world class reach through grey relational analysis", Grey Systems: Theory and Application, Vol. 8 No. 4, pp. 399-423.

Saunders, F.C. and Townsend, E.A. (2019), "Delivering new nuclear projects: a megaprojects perspective”, International Journal of Managing Projects in Business, Vol. 12 No. 1, pp. $144-160$.

Shi, Q., Liu, Y., Zuo, J., Pan, N. and Ma, G. (2015), “On the management of social risks of hydraulic infrastructure projects in China: A case study", International Journal of Project Management, Elsevier Ltd and International Project Management Association, Vol. 33 No. 3, pp. 483-496.

Sisirakumara, G.V. and Choy, C.S. (2018), "Knowledge management critical success factors and project management performance outcomes in major construction organisations in Sri Lanka: A case study", VINE Journal of Information and Knowledge Management Systems, Emerald Publishing Limited, Vol. 48 No. 4, pp. 537-558. 
Soja, P. (2010), "Understanding determinants of enterprise system adoption success: lessons learned from full-scope projects in manufacturing companies", Production Planning \& Control, Vol. 21 No. 8, pp. 736-750.

Suprapto, M., Bakker, H.L.M. and Mooi, H.G. (2015), "Relational factors in owner-contractor collaboration: The mediating role of teamworking", International Journal of Project Management, Vol. 33 No. 6, available at:https://doi.org/10.1016/j.ijproman.2015.03.015.

Todorović, M.L., Petrović, D.Č., Mihić, M.M., Obradović, V.L. and Bushuyev, S.D. (2015), "Project success analysis framework: A knowledge-based approach in project management", International Journal of Project Management, Pergamon, Vol. 33 No. 4, pp. 772-783.

Tomotani, J.V. and de Mesquita, M.A. (2018), "Lot sizing and scheduling: a survey of practices in Brazilian companies", Production Planning \& Control, Vol. 29 No. 3, pp. 236-246.

Vilventhan, A. and Kalidindi, S.N. (2018), "Utility relocation management in highway projects", Built Environment Project and Asset Management, Emerald Publishing Limited, Vol. 8 No. 2, pp. 171-182.

Wu, C., Li, N. and Fang, D. (2017), "Leadership improvement and its impact on workplace safety in construction projects: A conceptual model and action research", International Journal of Project Management, Vol. 35, pp. 1495-1511.

Yaghootkar, K. and Gil, N. (2012), "The effects of schedule-driven project management in multi-project environments", International Journal of Project Management, Pergamon, Vol. 30 No. 1, pp. 127-140.

Yahaya, W.I. and Qiping, S.G. (2020), "Stakeholder management in prefabricated prefinished volumetric construction projects: benchmarking the key result areas", Built Environment Project and Asset Management, Emerald Publishing Limited, Vol. 10 No. 3, pp. 407-421. Yang, L.R., Huang, C.F. and Hsu, T.J. (2014), “Knowledge leadership to improve project and organizational performance", International Journal of Project Management, Vol. 32 No. 1, available at:https://doi.org/10.1016/j.ijproman.2013.01.011.

Yin, R.K. (2014), Case Study Research: Design and Methods, 5th ed., SAGE Publications, Inc., Thousand Oaks.

Yng, L.F.Y., Yan, N., Hao, C.Y. and Zhe, Z. (2018), "Human resource management practices to improve project managers' job satisfaction", Engineering, Construction and Architectural Management, Emerald Publishing Limited, Vol. 25 No. 5, pp. 654-669.

Zhang, L. and Li, X. (2016), "How to reduce the negative impacts of knowledge heterogeneity in engineering design team: Exploring the role of knowledge reuse", International Journal 
of Project Management, Pergamon, Vol. 34 No. 7, pp. 1138-1149.

Zhao, Y. and Cao, H. (2015), "Risk management on joint product development with power asymmetry between supplier and manufacturer", International Journal of Project Management, Pergamon, Vol. 33 No. 8, pp. 1812-1826.

Zwikael, O., Pathak, R.D., Singh, G. and Ahmed, S. (2014), "The moderating effect of risk on the relationship between planning and success", International Journal of Project Management, Pergamon, Vol. 32 No. 3, pp. 435-441. 
Table 1: Difficulties in Project Management according to the literature (Source: see Table)

\begin{tabular}{|c|c|}
\hline Code & Definition \\
\hline D1 & $\begin{array}{l}\text { Difficulty in defining objectives and partition of them for teams (Ahsan and Gunawan, 2010; Butt et al., } \\
\text { 2016; Khamooshi and Golafshani, 2014; Lu and Wang, 2017; Martinsuo and Hoverfält, 2018; Oliveira et } \\
\text { al., 2018; Tomotani and de Mesquita, 2018; Yaghootkar and Gil, 2012) }\end{array}$ \\
\hline D2 & $\begin{array}{l}\text { Difficulty of integration and communication among the teams working on the project (Cheikhrouhou and } \\
\text { Marmier, 2010; Demirkesen and Ozorhon, 2017; Hui and Martin, 2020; Keegan et al., 2017; Larsson et } \\
\text { al., 2018; Ollus et al., 2011; Suprapto et al., 2015; Yng et al., 2018) }\end{array}$ \\
\hline D3 & $\begin{array}{l}\text { Difficulty in allocating human resources and defining responsibilities for team members (Al-jibouri, } \\
\text { 2002; Bryde et al., 2018; Haverila and Fehr, 2016; Iyer and Banerjee, 2016; Johansen and Rolstadås, } \\
\text { 2017; Keegan et al., 2017; Kissi et al., 2013; Love et al., 2018; Martinsuo and Hoverfält, 2018; } \\
\text { Matthews et al., 2018; Vilventhan and Kalidindi, 2018; Wu et al., 2017; Yang et al., 2014; Yng et al., } \\
\text { 2018) }\end{array}$ \\
\hline D4 & $\begin{array}{l}\text { Difficulty in defining the scope and managing changes of it (Afshin et al., 2019; Ahsan and Gunawan, } \\
\text { 2010; Iyer and Banerjee, 2016; Khamooshi and Golafshani, 2014; Martinsuo and Hoverfält, 2018; } \\
\text { Odasso et al., 1996; Soja, 2010; Tomotani and de Mesquita, 2018) }\end{array}$ \\
\hline D5 & $\begin{array}{l}\text { Difficulties in managing technical knowledge (Antony et al., 2012; Godfrey et al., 2018; Haverila and } \\
\text { Fehr, 2016; Hui and Martin, 2020; Lu and Wang, 2017; Martinsuo and Hoverfält, 2018; Oliveira et al., } \\
\text { 2018; Sajid and Usman, 2019; Sisirakumara and Choy, 2018; Wu et al., 2017; Yang et al., 2014; Zhang } \\
\text { and Li, 2016) }\end{array}$ \\
\hline D6 & $\begin{array}{l}\text { Difficulty of using software and tools to support decision making (Haverila and Fehr, 2016; Johansen } \\
\text { and Rolstadås, 2017; Love et al., 2018; Matthews et al., 2018; Montreuil and Poulin, 2005; Mu et al., } \\
\text { 2014; De Paula et al., 2019; Shi et al., 2015; Zhao and Cao, 2015; Zwikael et al., 2014) }\end{array}$ \\
\hline D7 & $\begin{array}{l}\text { Difficulty in structuring and managing schedule (Ahsan and Gunawan, 2010; Al-jibouri, 2002; Carlos } \\
\text { and Milton, 2014; Fossum et al., 2019; Iyer and Banerjee, 2016; Jäckel et al., 2006; Johansen and } \\
\text { Rolstadås, 2017; Keegan et al., 2017; Khamooshi and Golafshani, 2014; Love et al., 2018; Martinsuo } \\
\text { and Hoverfält, 2018; Myrelid, 2017; Tomotani and de Mesquita, 2018; Wu et al., 2017; Yaghootkar and } \\
\text { Gil, 2012) }\end{array}$ \\
\hline D8 & $\begin{array}{l}\text { Difficulty in managing financial resources (Ahsan and Gunawan, 2010; Atkinson, 1999; Butler et al., } \\
\text { 2018; Engwall and Jerbrant, 2003; Fossum et al., 2019; Haverila and Fehr, 2016; Iyer and Banerjee, } \\
\text { 2016; Lin et al., 2015; Lödding et al., 2014; Martinsuo and Hoverfält, 2018; Mu et al., 2014; Osei-Kyei } \\
\text { and Chan, 2015; Sanchez et al., 2017; Zhao and Cao, 2015) }\end{array}$ \\
\hline D9 & $\begin{array}{l}\text { Difficulty in managing risks (Boateng et al., 2015; Christopher and Leon, 2019; Cigolini and Rossi, } \\
\text { 2010; Crispim et al., 2019; Hwang et al., 2014; Mu et al., 2014; De Paula et al., 2019; Shi et al., 2015; } \\
\text { Zhao and Cao, 2015; Zwikael et al., 2014) }\end{array}$ \\
\hline D10 & $\begin{array}{l}\text { Difficulty in managing suppliers and other partners (Butt et al., 2016; Haverila and Fehr, 2016; Mu et } \\
\text { al., 2014; Myrelid, 2017; Olander, 2007; Oliveira et al., 2018; Rauch-Geelhaar et al., 2003) }\end{array}$ \\
\hline D11 & $\begin{array}{l}\text { Difficulty in managing project stakeholders (Butt et al., 2016; Chika et al., 2018, 2019; Gonzalez et al., } \\
\text { 2008; Jing et al., 2018; Lu and Wang, 2017; Olander, 2007; Oliveira } \text { et al., 2018; Rauch-Geelhaar } \text { et al., } \\
\text { 2003; Yahaya and Qiping, 2020; Zhai et al., 2009) }\end{array}$ \\
\hline D12 & $\begin{array}{l}\text { Difficulty in defining and prioritizing activities (Ahsan and Gunawan, 2010; Bryde et al., 2018; Butt et } \\
\text { al., 2016; Iyer and Banerjee, 2016; Johansen and Rolstadås, 2017; Keegan et al., 2017; Love } \text { et al., 2018; } \\
\text { Lu and Wang, 2017; Martinsuo and Hoverfält, 2018; Oliveira et al., 2018; Osei-Kyei and Chan, 2015; } \\
\text { Yang } \text { et al., 2014) }\end{array}$ \\
\hline
\end{tabular}


Table 2. Grey Relational Generating - normalized values of the scores (Source: Authors)

\begin{tabular}{|c|c|c|c|c|c|c|c|c|c|c|c|c|}
\hline$\#$ & D1 & D2 & D3 & D4 & D5 & D6 & D7 & D8 & D9 & D10 & D11 & D12 \\
\hline 1 & 0.700 & 1.000 & 0.300 & 0.500 & 0.000 & 0.300 & 0.300 & 0.800 & 0.600 & 0.600 & 0.700 & 0.400 \\
\hline 2 & 0.667 & 0.889 & 0.000 & 0.778 & 0.111 & 0.000 & 1.000 & 0.222 & 0.000 & 0.556 & 0.778 & 0.111 \\
\hline 3 & 0.800 & 0.800 & 0.000 & 0.400 & 0.200 & 0.000 & 0.400 & 0.000 & 0.000 & 1.000 & 0.600 & 0.800 \\
\hline
\end{tabular}


Table 3 - Difference of each element in Table 2 to the reference (Source: Authors)

\begin{tabular}{|c|c|c|c|c|c|c|c|c|c|c|c|c|}
\hline$\#$ & D1 & D2 & D3 & D4 & D5 & D6 & D7 & D8 & D9 & D10 & D11 & D12 \\
\hline 1 & 0.300 & 0.000 & 0.700 & 0.500 & 1.000 & 0.700 & 0.700 & 0.200 & 0.400 & 0.400 & 0.300 & 0.600 \\
\hline 2 & 0.333 & 0.111 & 1.000 & 0.222 & 0.889 & 1.000 & 0.000 & 0.778 & 1.000 & 0.444 & 0.222 & 0.889 \\
\hline 3 & 0.200 & 0.200 & 1.000 & 0.600 & 0.800 & 1.000 & 0.600 & 1.000 & 1.000 & 0.000 & 0.400 & 0.200 \\
\hline
\end{tabular}


Table 4. Grey Relational Coefficients and Grey Relational Grade (Source: Authors)

\begin{tabular}{|c|c|c|c|c|c|c|c|c|c|c|c|c|}
\hline$\#$ & D1 & D2 & D3 & D4 & D5 & D6 & D7 & D8 & D9 & D10 & D11 & D12 \\
\hline 1 & 0.625 & 1.000 & 0.417 & 0.500 & 0.333 & 0.417 & 0.417 & 0.714 & 0.556 & 0.556 & 0.625 & 0.455 \\
\hline 2 & 0.600 & 0.818 & 0.333 & 0.692 & 0.360 & 0.333 & 1.000 & 0.391 & 0.333 & 0.529 & 0.692 & 0.360 \\
\hline 3 & 0.714 & 0.714 & 0.333 & 0.455 & 0.385 & 0.333 & 0.455 & 0.333 & 0.333 & 1.000 & 0.556 & 0.714 \\
\hline R & 0.646 & 0.844 & 0.361 & 0.549 & 0.359 & 0.361 & 0.624 & 0.480 & 0.407 & 0.695 & 0.624 & 0.510 \\
\hline
\end{tabular}


Table 5. Comparative ordering of difficulties via Grey Relational Grade (Source: Authors)

\begin{tabular}{|c|c|c|}
\hline Rank & $\mathbf{R}$ & Difficulty \\
\hline $1^{\circ}$ & 0.844 & $\mathrm{D} 2$ \\
\hline $2^{\circ}$ & 0.695 & $\mathrm{D} 10$ \\
\hline $3^{\circ}$ & 0.646 & $\mathrm{D} 1$ \\
\hline $4^{\circ}$ & 0.624 & $\mathrm{D} 11$ \\
\hline $5^{\circ}$ & 0.624 & $\mathrm{D} 7$ \\
\hline $6^{\circ}$ & 0.549 & $\mathrm{D} 4$ \\
\hline $7^{\circ}$ & 0.510 & $\mathrm{D} 12$ \\
\hline $8^{\circ}$ & 0.480 & $\mathrm{D} 8$ \\
\hline $9^{\circ}$ & 0.407 & $\mathrm{D} 9$ \\
\hline $10^{\circ}$ & 0.361 & $\mathrm{D} 3$ \\
\hline $11^{\circ}$ & 0.361 & $\mathrm{D} 6$ \\
\hline $12^{\circ}$ & 0.359 & $\mathrm{D} 5$ \\
\hline
\end{tabular}




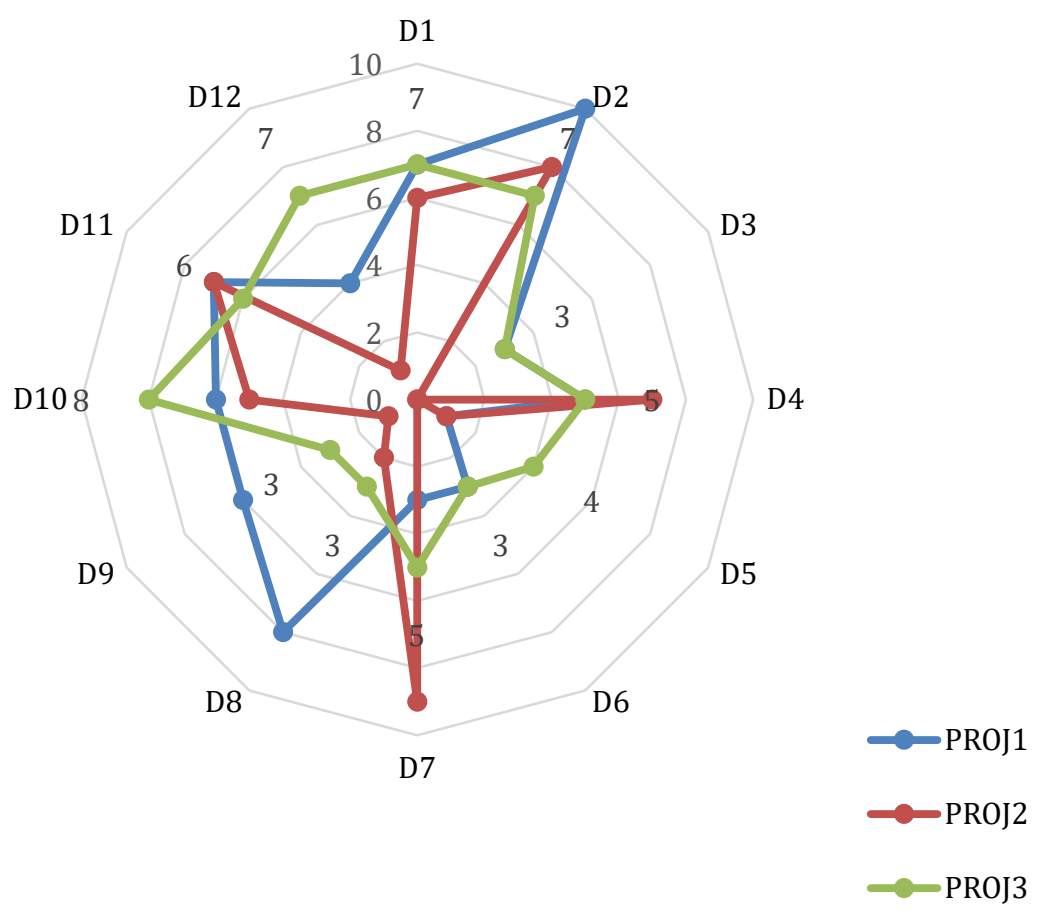

Figure 1. Scores attributed by managers for each difficulty (Source: Authors) 